
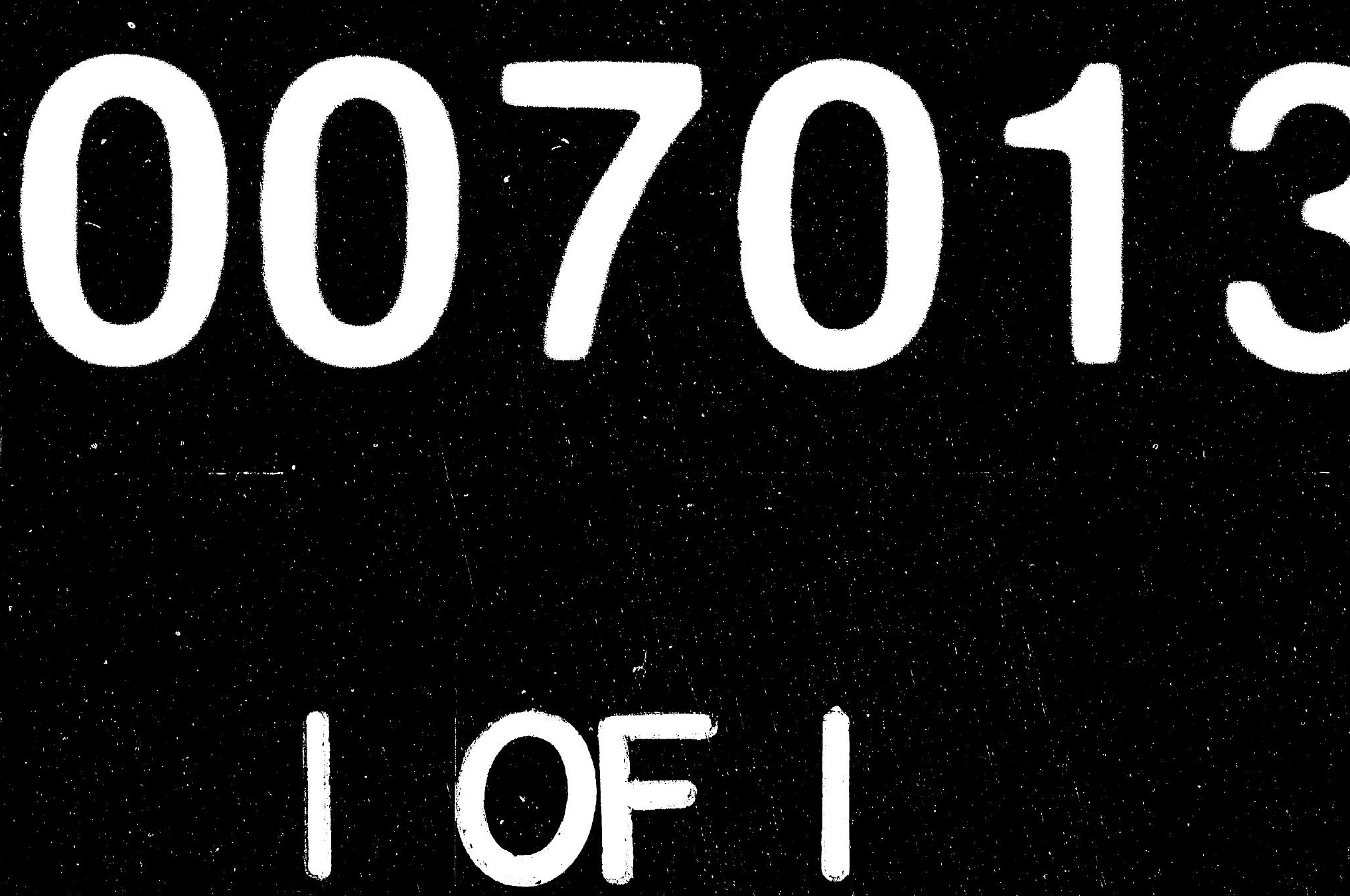

1

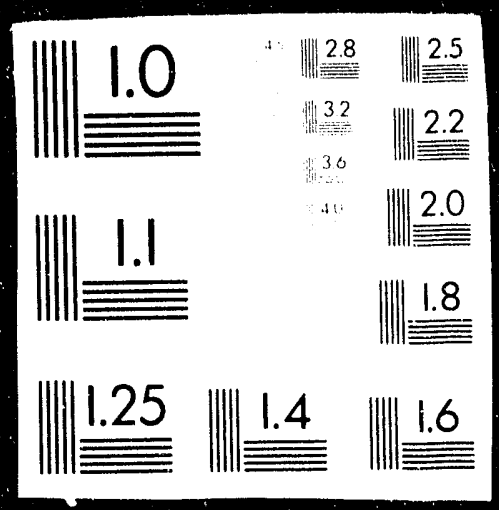




$$
\text { Dos/ER/14/22-1 }
$$

DOE/ER/14122--1

DE93 007013

\section{FINAL REPORT DOE DE-FG02-90ER14122}

\section{DISCLAIMER}

This report was prepared as an account of work sponsored by an agency of the United States Government. Neither the United States Government nor any agency thereof, nor any of their employees, makes any warranty, express or implied, or assumes any legal liability or responsibility for the accuracy, completeness, or usefulness of any information, apparatus, product, or process disclosed, or represents that its use would not infringe privately owned rights. Reference herein to any specific commercial product, process, or service by trade name, trademark, manufacturer, or otherwise does not necessarily constitute or imply its endorsement, recommendation, or favoring by the United States Government or any agency thereof. The views and opinions of authors expressed herein do not necessarily state or reflect those of the United States Government or any agency thereof.

\section{MASTER}




$$
0 . \varepsilon / \varepsilon / 14 / 22-1
$$

\section{Project Overview:}

\section{A. Project Objectives}

New synthetic methods for the preparation of persistent transition metal centered radicals have been developed based on ligand addition reactions of triphenylmethyl complexes. Preliminary study of the reactivity of selected examples indicate that they will react under mild conditions with substrates such as hydrogen and certain hydrocarbons. The chemistry has been extended to biradicals. The proposed research is primarily directed to understanding the mechanism and selectivity of these novel reactions. Extensions and modification of the synthetic method to provide additional examples of persistent radicals are proposed. More general methodologies including the reduction of metal halides are also being developed.

\section{Background information:}

The reaction of transition metal complexes with hydrogen has received increased attention recently. This reaction is extremely important in the context of homogeneous catalysis of hydrogenation reactions. Since the seminal discoveries by Kubas of coordination of intact dihydrogen as a ligand to transition metal complexes, there has been considerable activity in this area. A large number of complexes are now known with $\mathrm{H}_{2}$ acting as a side bound ligand. All these complexes are diamagnetic, and have been primarily characterized by solution NMR methods. There are no examples of coordination of $\mathrm{H}_{2}$ to a paramagnetic metal center, although such complexes have been proposed to be important in metalloenzymes which react with hydrogen. We have developed convenient methods for the thermal synthesis of persistent $\operatorname{Re}(0)$ radicals of the form $\cdot \operatorname{Re}(\mathrm{CO})_{3}(\mathrm{~L})_{2}(\mathrm{~L}=$ tertiary phosphine ligand). We have found that these $\operatorname{Re}(0)$ radicals react with hydrogen readily to effect homolytic cleavage of $\mathrm{H}_{2}$ to two metal hydrides. There are preliminary indications that this reaction may proceed via a 19 electron complex of $\mathrm{H}_{2}$. The extension of this work to biradicals has also given some intriguing results. Further investigations of the mechanism of these reactions are proposed.

The problem of homogeneous activation and functionalization of the $\mathrm{C}-\mathrm{H}$ bonds of saturated hydrocarbons by transition metal complexes has been the subject of intense research efforts in recent years. Considerable progress has been made using the photochemical or thermal generation of unsaturated ( 16 electron or 14 electron) intermediates. These very reactive intermediate species then react with the hydrocarbon substrate via oxidative addition of the C-H bonds. Due to the shor lifetimes of the intermediates, characterization is difficult, but some progress has been made using matrix isolation methods and fast spectroscopy techniques. Considerable indirect evidence exists for " $\sigma$ complexes" of alkanes as intermediates along the reaction pathway.

Another approach to the problem which has been much less explored is the use of metal centered radicals to activate $\mathrm{C}-\mathrm{H}$ bonds. In principle, the reaction of a hydrocarbon (e.g. methane) with a metal radical (equation 1 ) is thermodynamically feasible if the sum of the $\mathrm{M}-\mathrm{H}$ and $\mathrm{M}-\mathrm{CH}_{3}$ bond enthalpies is greater than the $\mathrm{H}-\mathrm{CH}_{3}$ bond enthalpy $\left(104 \mathrm{kcal} \mathrm{mol}^{-1}\right)$.

$$
2 \mathrm{M} \cdot+\mathrm{H} \cdot \mathrm{CH}_{3} \rightarrow \mathrm{M} \cdot \mathrm{H}+\mathrm{M} \cdot \mathrm{CH}_{3}
$$


Although quantitative data is sketchy, this criterion is probably met by third row transition metals and by some second row metals as well. Our results on homolytic hydrogen activation indicate that the $\mathrm{Re}-\mathrm{H}$ bond strength in these systems must be at least $52 \mathrm{kcalmol}^{-1}$ (ie. half of the $\mathrm{H}-\mathrm{H}$ bond strength). Calorimetric data indicates the $\mathrm{Re}-\mathrm{C}$ bond strengths in alkyls of this type will be ca. 55 $\mathrm{kcalmol}^{-1}$, so the homolytic activation of $\mathrm{C}-\mathrm{H}$ bonds by these radicals is thermodynamically feasible. A bond strenth of $75 \mathrm{kcalmol}^{-1}$ for $\operatorname{Re}(\mathrm{CO})_{5}-\mathrm{H}$ was recently reponed by Parker and Tilset. Thus the homolytic activation of $\mathrm{C}-\mathrm{H}$ bonds by these radicals is thermodynamically feasible and exothermicity of $\mathrm{ca} .26 \mathrm{kcalmol}^{-1}$ would be anticipated even for the strong C-H bond of methane. Achieving reactions such as equation 1 is really a kinetic problem. The radicals must have a sufficiently long lifetime (versus undesirable side reactions such as dimerization) to effect the desired reaction with a hydrocarbon. There were until very recently no reports of radical based systems which will react with the very unreactive aliphatic $\mathrm{C}$ - $\mathrm{H}$ bonds of substrates such as methane. This reaction has now been achieved by Wayland and coworkers using a sterically encumbered rhodium porphyrin system.(J. Am. Chem. Soc. 1990, 112, 1259-1260; J. Am. Chem. Soc. 1991, 113, 5305-5311.)

\section{Results From the First Funding Period}

We have developed a convenient method for the thermal synthesis of metal centered radicals which employs the trityl radical $\left(\mathrm{Ph}_{3} \mathrm{C} \cdot\right)$ as a leaving group. The key starting material for this chemistry is $\left(\eta^{3}-\mathrm{CPh}_{3}\right) \operatorname{Re}(\mathrm{CO})_{4},(1)$, which is prepared from $\mathrm{NaRe}(\mathrm{CO})_{5}$ and $\mathrm{Ph}_{3} \mathrm{CPF}_{6}$ (eq 2)

$$
\begin{aligned}
& \mathrm{NaRe}(\mathrm{CO})_{5}+\mathrm{Ph}_{3} \mathrm{CPF}_{6} \rightarrow\left(\eta^{3}-\mathrm{CPh}_{3}\right) \mathrm{Re}(\mathrm{CO})_{4}+\mathrm{CO}+\mathrm{NaPF}_{6} \text { (2) } \\
& 1
\end{aligned}
$$

The characterization and solid state structure of 1 has been reponed.

Reaction of 1 with donor ligands $\mathrm{L}$ at room temperature affords $\operatorname{Re}(0)$ radicals and $\mathrm{Ph}_{3} \mathrm{C} \cdot$. In order to prepare persistent radicals, they must be stabilized against dimerization by the incorporation of bulky phosphine ligands. To achieve this, 1 is decarbonylated by refluxing in THF to give $\left(\eta^{5}-\mathrm{CPh}_{3}\right) \operatorname{Re}(\mathrm{CO})_{3},(2)$, which has the structure shown in equation 4.

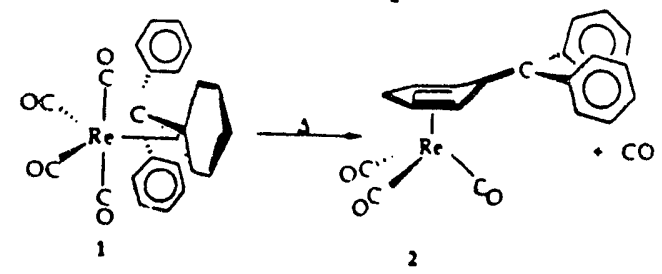

The reaction of 2 with two equivalents of a bulky phosphine ligand such as $\mathrm{PCy}$ or $\mathrm{P}(i-\mathrm{Pr})_{3}$ affords the persistent radicals $\cdot \operatorname{Re}(\mathrm{CO})_{3}\left(\mathrm{PCy}_{3}\right)_{2},(3)$, and $\cdot \operatorname{Re}(\mathrm{CO})_{3}\left(\mathrm{P}(\mathrm{i}-\mathrm{Pr})_{3}\right)_{2},(4)$. Radicals of this type have been previously observed in solution, but have not been isolated, presumably due to the limitations of the photochemical synthesis which was employed. The solid state structure of 3 has been determined(Figure I).

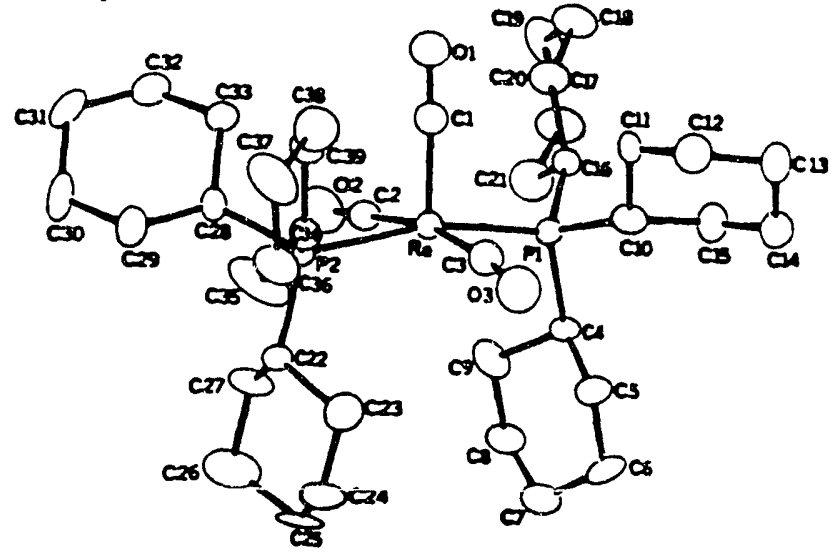


The EPR spectrum of 3 indicates a large coupling to $\operatorname{Re}(I=5 / 2)$, and the expected triplet due to coupling to two ${ }^{31} \mathrm{P}$ nuclei has been resolved in the third hyperfine line, indicating some delocalization of the unpaired electron into the phosphine ligands. Further experiments have been carried out with fully ${ }^{13} \mathrm{CO}$ labelled samples of 3 with the surprising result that no coupling of the unpaired electron to ${ }^{13} \mathrm{C}$ was observed. This result was unexpected, since calcualations by Hoffman and coworkers have shown that the unpaired electron in $\cdot \operatorname{Re}(\mathrm{CO})_{5}$ resides in a sigma orbital $\left(a_{1}\right.$ in $\mathrm{C}_{4 \mathrm{v}}$ ) which has considerable mixing into the $\pi$ system of the equatorial ligands. Thus the distribution of spin density in these species is fundamentally different from that observed by Wayland and coworkers in the $\mathrm{Rh}$ (porphyrin)CO complexes. Consistent with this observation, these complexes show no tendency to dimerize through the CO ligands.

Preliminary studies of the reactivity of 3 and 4 show that they react instantaneously with $C O$ to give loss of one phosphine ligand, followed by rapid dimerization of the resulting $\cdot \operatorname{Re}(\mathrm{CO})_{4} \mathrm{PR}_{3}$ radical(equation 5). This reaction with $\mathrm{CO}$ likely proceeds via an associative mechanism with a formally nineteen electron intermediate, as has been established for the case of $\cdot \operatorname{Re}(\mathrm{CO})_{5}$.

$$
2 \cdot \operatorname{Re}(\mathrm{CO})_{3}\left(\mathrm{PR}_{3}\right)_{2}+2 \mathrm{CO} \rightarrow \mathrm{Re}_{2}(\mathrm{CO})_{8}\left(\mathrm{PR}_{3}\right)_{2}+2 \mathrm{PR}_{3}
$$

The radicals also react rapidly with $\mathrm{H}$ atom donors such as $\mathrm{Ph}_{3} \mathrm{SnH}$ to give the corresponding neutral hydrides(equation 6).

$$
2 \cdot \operatorname{Re}(\mathrm{CO})_{3}\left(\mathrm{PR}_{3}\right)_{2}+2 \mathrm{Ph}_{3} \mathrm{SnH} \rightarrow \mathrm{H}-\mathrm{Re}(\mathrm{CO})_{3}\left(\mathrm{PR}_{3}\right)_{2}+\left(\mathrm{Ph}_{3} \mathrm{Sn}\right)_{2}(6)
$$

The hydrides formed have been characterized fully. Protonation of the neutral hydrides at low temperature affords the cationic $\mathrm{H}_{2}$ complexes isoelectronic to the $\mathrm{W}(0)$ complexes prepared by Kubas and coworkers. The retention of the $\mathrm{H}-\mathrm{H}$ bond in these species was verified by the observation of $J_{H-D}=28-29 \mathrm{~Hz}$ in the H-D derivatives. These dihydrogen complexes were not isolable. Decomposition via loss of $\mathrm{H}_{2}$ occurs above $-20^{\circ} \mathrm{C}$, indicating that the binding of $\mathrm{H}_{2}$ to the cationic metal center is relatively weak.

Interestingly, the same neutral hydrides are obtained when the radicals are reacted with hydrogen. That the hydrogen gas is the source of the hydride ligand was confirmed by reaction of the radicals with $\mathrm{D}_{2}$. In this case, the corresponding deuterides were obtained. When the reaction of 3 with $\mathrm{H}_{2}$ was carried out in the presence of trityl radical, triphenylmethane was obtained. In a control experiment, no reaction was detected between hydrogen and trityl radical in the absence of 3 . A separate experiment confirmed that the trityl radical does not react with $\mathrm{H} \cdot \operatorname{Re}(\mathrm{CO})_{3}\left(\mathrm{PR}_{3}\right)$. These results may indicate that the reaction proceeds via a formally nineteen electron complex of $\mathrm{H}_{2}$, in which the coordination of $\mathrm{H}_{2}$ facilitates the homolysis.

This homolytic cleavage of $\mathrm{H}_{2}$ by metal centered radicals has some precedent in the literature. Previous workers have proposed a termolecular mechanism for a similar reaction of the related $d^{7}$ $\mathrm{Co}(\mathrm{CN}) 5_{5}^{3-}$ radicals. Several experiments are planned to elucidate the mechanism of the reaction of the $\operatorname{Re}(0)$ radicals with hydrogen and to seek evidence for an intermediate $\mathrm{H}_{2}$ complex.

In exploring the reactions of $\mathbf{3}$ with hydrocarbons, we have found that the radical reacts with methane in refluxing benzene- $d_{6}$ to give the corresponding hydride.(eq. 7)

$$
2 \cdot \operatorname{Re}(\mathrm{CO})_{3}\left(\mathrm{PCy}_{3}\right)_{2}+\mathrm{CH}_{4} \rightarrow \mathrm{H} \cdot \mathrm{Re}(\mathrm{CO})_{3}\left(\mathrm{PCy}_{3}\right)_{2}
$$


The hydride has been identified by ${ }^{1} \mathrm{H}$ NMR comparison to the product of the tin hydride reaction(vide supra). The same product is formed when the reaction is carried out with fully deuterated ligands $\left(\mathrm{PCy}_{3}-\mathrm{d}_{33}\right)$. When the reaction was carried out with $\mathrm{CD}_{4}$, the corresponding rhenium deuteride was obtained. In the absence of methane under the same conditions, no reaction occurs. While these observations may indicate that a reaction with methane is occuring, it is puzzling that the corresponding methyl complex $\mathrm{CH}_{3}-\mathrm{Re}(\mathrm{CO})_{3}\left(\mathrm{PCy}_{3}\right)_{2}$ is not formed. In order to confirm the expected thermal stablility of this methyl complex, it was independently prepared by thermal ligand substitution with $\mathrm{CH}_{3}-\mathrm{Re}(\mathrm{CO})_{5}$. (eq. 8)

$$
\mathrm{CH}_{3}-\mathrm{Re}(\mathrm{CO})_{5}+2 \mathrm{PCy}_{3} \rightarrow \mathrm{CH}_{3}-\mathrm{Re}(\mathrm{CO})_{3}\left(\mathrm{PCy}_{3}\right)_{2}+2 \mathrm{CO}
$$

As expected, the methyl complex is stable to the reaction conditions. Further, when an equimolar mixture of the methyl complex and the hydride was heated to reflux in toluene for 30 days, no reaction was observed. (eq. 9)

$$
\mathrm{CH}_{3}-\mathrm{Re}(\mathrm{CO})_{3}\left(\mathrm{PCy}_{3}\right)_{2}+\mathrm{H}-\mathrm{Re}(\mathrm{CO})_{3}\left(\mathrm{PCy}_{3}\right)_{2} \rightarrow \text { no reaction (9) }
$$

This observation stands in contrast to those of Wayland and Sherry, where the activation of methane by the rhodium porphyrin complexes is reversible.

Since no methyl complex was detected in the apparent reaction with methane, the fate of the methyl group was investigated. No ethane or ethylene w'as detected by NMR of the reaction solution or gas chromatography of the headspace gases. The methane samples employed in these experiments were of very high purity and were further purified by prolonged stirring over molten potassium. No hydrogen was detectable in the methane gas by gas chromatography.

Examination of space filling model represenations of 3 leads to the conclusion that the coordination sphere around the metal is very crowded. On the assumption that steric hindrance is limiting the reactivity of the $R e$ radicals, we have attempted to prepare the radicals with less sterically demanding phosphine ligands. Thus reaction of 2 with $\mathrm{PPh}_{3}$ gives a blue solution apparently containig a thenium centered radical which affords an EPR spectrum similar to that of 3. Unfortunately the radical dimerizes with a half life of about ten minutes at room temperature. The dimerization is apparently irreversible. Efforts are underway to prepare suitable ligands to allow for the synthesis of radicals which are stable to dimerization but sufficiently sterically unencumbered to react with hydrocarbons under mild conditions.

Brown and coworkers have reported the preparation and properties of transient Re centered biradicals which are generated by photolysis of $\operatorname{Re}$ dimers. These biradicals have very short lifetimes(ca. $10^{-7}$ seconds). Their reactivity is similar to the related monoradicals.

Using the synthetic methodology outlined above for the monoradicals, we have developed a convenient preparation for persistent biradicals, which employs a bidentate phosphine ligand, abbreviated as P.-P $(\mathrm{R}=$ cyclohexyl $)$.

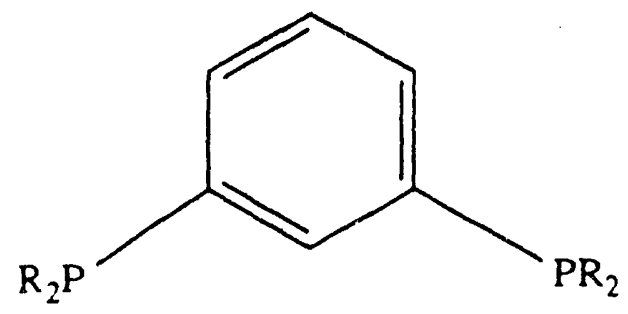


This new phosphine ligand meets two requirements: 1) The bulky cyclohexyl groups prevent dimerization via formation of Re-Re bonds. 2) The P-P linkage is rigid with a P-P separation of 5.5 $\AA$. This imposes a metal-metal separation of about $5 \AA$, thus preventing the formation of a $\operatorname{Re}-\operatorname{Re}$ bond. Reaction of P-.P with 2 affords the biradical 5 (eq. 9).

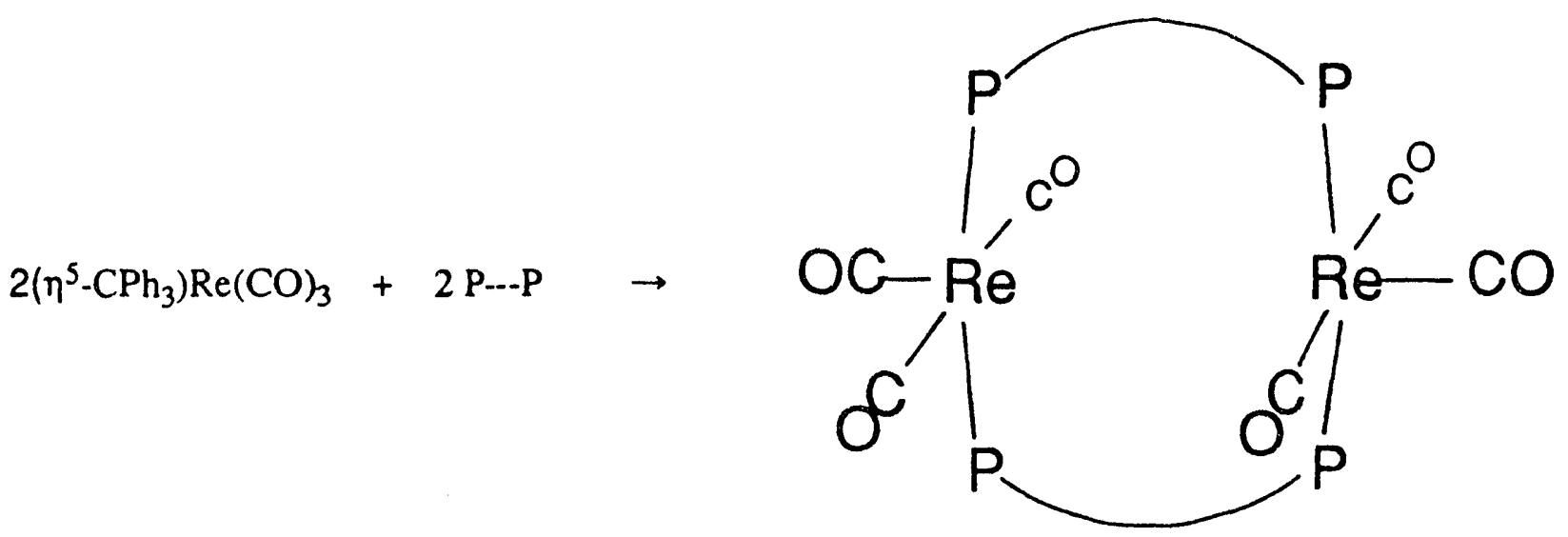

The biradical 5 has limited solubility in solvents such as benzene and toluene. We have not yet obtained crystals of 5 suitable for X-ray diffraction study, but the EPR spectrum of 5 is similar to that of the monoradicals mentioned above, indicating no significant interaction between the unpaired electrons on the adjacent metal centers.

The biradical 5 reacts with $\mathrm{H}_{2}$ to give the binuclear dihydride 6 . Complex 6 can also be prepared by reaction of 5 with $\mathrm{Ph}_{3} \mathrm{Sn}-\mathrm{H}$. Qualitative observations indicate that the reaction of 5 with $\mathrm{H}_{2}$ is much faster than the analogous reaction of the monoradicals, perhaps indicating some cooperative effects in this reaction. The ${ }^{1} \mathrm{H}$ NMR spectrum of 6 in the hydride region gives a simple triplet, indicating equal coupling to two ${ }^{31} \mathrm{P}$ nuclei, as was observed for the monomeric hydrides. There is

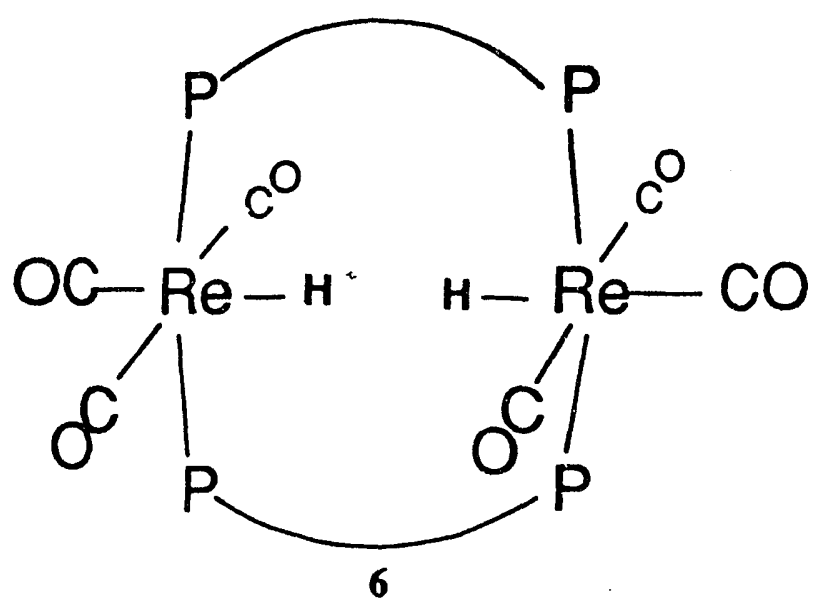

no evidence of coupling between the hydride and the $P$ nuclei on the adjacent metal. 
Proposed Research for 1992 and 1993

A preliminary examination of the EPR spectra of 3 and 4 shows that the spectra are qualitatively quite similar, being dominated by the large coupling to rhenium. Presumably, the coupling exhibited by the unpaired electron to ${ }^{31} \mathrm{P}$ will be very sensitive to slight structural variations in the complexes. We plan to carry out the EPR characterization of samples of the radicals produced by the reaction of various phosphines ligands $\mathrm{L}\left(\mathrm{L}=\mathrm{PPh}_{3}\right.$, cone angle 145 ; $\mathrm{PPh}_{2}(t-\mathrm{Bu}), 157^{\circ} ; \mathrm{PPh}(\mathrm{l}-\mathrm{Bu})_{2}, 170^{\circ}$; $\left.\mathrm{P}(t-\mathrm{Bu})_{3}, 182^{\circ} \mathrm{C}\right)$ with $\left(\eta^{5}-\mathrm{CPh} h_{3}\right) \operatorname{Re}(\mathrm{CO})_{3}$. For the smaller phosphines such as $\mathrm{PPh}_{3}$, the radicals will be transient species unstable with respect to dimerization. Only a small concentration in solution in toluene is required, since the solution can then be frozen to a glass for the EPR experiment. We hope to gain a better understanding of the structural variations in these radicals as a function of ligand from these experiments. In the case of persistent radicals, the UV/Vis spectra and IR spectra in the carbonyl region may also provide some structural information. Additional X-ray diffraction studies will also be undertaken if suitable crystals can be obtained. We have obtained small crystals of 4 , but to date they have not been of sufficiently high quality for diffraction experiments. Single crystal EPR experiments may be possible for 3 by doping this radical into a diamagnetic host, such as the isostructural diamagnetic tungsten compound reported by Kubas and coworkers.

\section{Reaction with Hydrogen}

As discussed above, preliminary evidence indicates that the reaction of $\mathrm{H}_{2}$ with 3 may take place via a nineteen electron $\mathrm{H}_{2}$ complex. The qualitative observation that $4\left(\mathrm{~L}=\mathrm{P}(i \text {-Pr })_{3}\right)$ reacts more rapidly with $\mathrm{H}_{2}$ than does 3 is consistent with this mechanism, but is also consistent with the termolecular reaction mechanism favored by Halpern. In the case of the related $d^{7}$ radical $\mathrm{Co}(\mathrm{CN})_{5}{ }^{3-}$, which reacts with $\mathrm{H}_{2}$ under somewhat more vigorous conditions to give homolytic cleavage of $\mathrm{H}_{2}$, kinetic studies led Halpern to postulate a termolecular reaction mechanism, since the rate law for the reaction has the form rate $=\mathrm{k}\left[\mathrm{H}_{2}\right][\mathrm{Co} \cdot]^{2}$. We have considered the alternative possibility that the reaction could proceed stepwise, via a rapid pre-equilibrium step involving a 19 electron hydrogen complex of the radical, followed by rate limiting hydrogen atom abstraction from this complex by a second metal radical.(equation 10 and 11 )

$$
\begin{gathered}
\cdot \operatorname{Re}(\mathrm{CO})_{3}\left(\mathrm{PR}_{3}\right)_{2}+\mathrm{H}_{2} \leftrightharpoons\left(\mathrm{H}_{2}\right) \operatorname{Re}(\mathrm{CO})_{3}\left(\mathrm{PR}_{3}\right)_{2} \quad(10) \\
\left(\mathrm{H}_{2}\right) \operatorname{Re}(\mathrm{CO})_{3}\left(\mathrm{PR}_{3}\right)_{2}+\cdot \operatorname{Re}(\mathrm{CO})_{3}\left(\mathrm{PR}_{3}\right)_{2} \rightarrow 2 \mathrm{H} \cdot \operatorname{Re}(\mathrm{CO})_{3}\left(\mathrm{PR}_{3}\right)_{2}
\end{gathered}
$$

This scheme will give a rate law of the form rate $=k_{2} K_{e q}\left[\mathrm{H}_{2}\right][\mathrm{Re} \cdot]^{2} /\left(1+k_{2} / k_{-1} \cdot[\operatorname{Re} \cdot]\right)$, where $\mathrm{K}_{\mathrm{eq}}=$ $k_{1} / k_{-1}$ is the equilibrium constant for equation 10 and $k_{2}$ is the rate constant for the rate determining step represented by equation 11 . This mechanism will be kinetically indistinguishable from the termolecular process at low [Re-], but will show a change from second order dependence on the radical concentration to first order dependence at some high value of $[\operatorname{Re} \cdot]$. The concentration of radical required to exhibit this effect will depend upon the value for $K_{\text {eq. }}$. We plan to carry out a kinetic study of the reaction of 3 or 4 with $\mathrm{H}_{2}$ over a wide range of radical concentrations. The extent of reaction will be readily assayed by the visible spectrum $\left(\lambda_{\max }\right.$ at $661 \mathrm{~nm}, \epsilon=365 \mathrm{M}^{-1} \mathrm{~cm}^{-1}$ for 3 ) of the reaction mixture. 
In addition to the kinetic experiments, we hope to obtain direct evidence for the interaction of $\mathrm{H}_{2}$ with the rhenium radicals by spectroscopic methods. If $\mathrm{K}_{\text {eq }}$ for equation 10 is $10^{-4}$ or greater, signals due to the hydrogen complex may be directly detectable in the EPR spectrum. Sensitivity to a minor species will be maximized by recording the spectrum of a dilute sample of the radical in a toluene glass prepared in the absence of $\mathrm{H}_{2}$, then observing the spectrum of the same sample in the presence of approximately equimolar $\mathrm{H}_{2}$. The difference spectrum will hopefully show signals due to the $\mathrm{H}_{2}$ complex.

Alternatively, we will seek evidence for the interaction of $\mathrm{H}_{2}$ with the radicals by examining the relaxation behavior of the $\mathrm{H}_{2}$ by proton NMR. The spin lattice relaxation time $\left(\mathrm{T}_{1}\right)$ for $\mathrm{H}_{2}$ in solution is quite long, ca. $1.6 \mathrm{sec}$. The relaxation of the $\mathrm{H}_{2}$ bound to the paramagnetic rhenium center will be extremely rapid (ca. 1 msec or less). If it is assumed that exchange between $\mathrm{H}_{2}$ coordinated to the rhenium and free $\mathrm{H}_{2}$ in solution is relatively rapid, the $\mathrm{T}_{1}$ observed for the $\mathrm{H}_{2}$ will be shortened. This effect can be distinguished from simple proximity effects by studying the concentration dependence and by using different $\mathrm{Re}$ radicals, which presumably will have various values for $\mathrm{K}_{\mathrm{eq}}$.

The interesting observation that $\mathrm{H}_{2}$ reacts with $\mathrm{Ph}_{3} \mathrm{C}$. in the presence of $\mathrm{Re}$ radicals but not in their absence was mentioned in the previous results section. If our interpretation of the mechanism of the reaction of the radicals with $\mathrm{H}_{2}$ is correct, this reaction represents a striking activation of $\mathrm{H}_{2}$ toward homolytic cleavage upon coordination to the metal. This result is quite distinct from the previous reports of activation of $\mathrm{H}_{2}$ toward heterolysis upon coordination to cationic transition metal centers. An alternative explanation which must be considered is that the reaction occurs via a termolecular mechanism involving $\mathrm{H}_{2}, \mathrm{Ph}_{3} \mathrm{C}$. and the thenium radical. Again, these two possibilities can be distinguished kinetically by studying the rate of the reaction as a function of $\left[\mathrm{Ph}_{3} \mathrm{C} \cdot\right]$. The termolecular mechanism will give a rate law of the form rate $=k[R e \cdot]\left[\mathrm{H}_{2}\right]\left[\mathrm{Ph}_{3} \mathrm{C} \cdot\right]$. The mechanism involving the intermediacy of the $\mathrm{H}_{2}$ complex will give rate $=\mathrm{k}_{2} \mathrm{~K}_{\text {eo }}[\mathrm{Re} \cdot]\left[\mathrm{H}_{2}\right]\left[\mathrm{Ph}_{3} \mathrm{C} \cdot\right] /(1+$ $\left.\mathrm{k}_{2} / \mathrm{k}_{-1}\left[\mathrm{Ph}_{3} \mathrm{C} \cdot\right]\right)$. The rate will be first order in $\left[\mathrm{Ph}_{3} \mathrm{C} \cdot\right]$ at low values of $\left[\mathrm{Ph}_{3} \mathrm{C} \cdot\right]$, but will become independent of $\left[\mathrm{Ph}_{3} \mathrm{C} \cdot\right]$ at some high value of $\left[\mathrm{Ph}_{3} \mathrm{C} \cdot\right]$. The concentration dependent dimerization of the trityl radical is well studied and can be corrected for.

If evidence is obtained for the intermediacy of the $\mathrm{H}_{2}$ complex in the experiments outlined above, we plan to measure kinetic isotope effects for the homolytic cleavage of hydrogen by studying the reaction of $\mathrm{H}_{2} / \mathrm{D}_{2}$ mixtures with $\mathrm{Ph}_{3} \mathrm{C}$. in the presence of rhenium radicals. It must first be established that the radicals do not equilibrate $\mathrm{HD}$ with $\mathrm{D}_{2}$ and $\mathrm{H}_{2}$, although this seems unlikely. The kinetic isotope effect will be measured by examining the triphenylmethane formed by mass spectroscopy to determine the ratio of $\mathrm{Ph}_{3} \mathrm{C}-\mathrm{H}$ to $\mathrm{Ph}_{3} \mathrm{C}-\mathrm{D}$. As a check, the ratio of $\left(\mathrm{PR}_{3}\right)_{2}(\mathrm{CO})_{3} \mathrm{Re}-\mathrm{H}$ to the corresponding deuteride can be determined by ${ }^{31} \mathrm{P}$ NMR.(these two species are easily distinguished by ${ }^{31} \mathrm{P}$ NMR.) If H-H (D-D) bond cleavage is involved in the rate determining step, there may be a substantial kinetic isotope effect, which may in fact be an inverse effect $\left(k_{K}<k_{D}\right)$. Such inverse kinetic isotope effects have been observed in alkane $\mathrm{C}-\mathrm{H}$ bond activation reactions which proceed via the intermediacy of alkane complexes. In this case, such an effect would be a manifestation of a thermodynamic isotope effect upon $K_{\text {eq }}$ for equation 10 . 
These distance estimates are based on the Re-P distances and angles that we have observed in the solid state structure of 3 . Although the ligand systems have been selected for their relatively rigid structures, some degree of flexibility will presumably be possible in solution. The distances quoted will represent energy minima. At ambient temperatures, a range of structures having various metal-metal separations will be thermally accessible. This is demonstrated by the fact that the biradical 5 reacts with hydrogen even though the equilibrium $R e-R e$ separation is greater than $5 \AA$. Given that the H-H separation in hydrogen is $.75 \AA$ and typical $\mathrm{Re}-\mathrm{H}$ distances are $1.6 \AA$, it would seem that a structure having a $\operatorname{Re}-\operatorname{Re}$ separation of slightly greater than $4 \AA$ must be thermally accessible.

The new biradical systems will be characterized by EPR measurements and hopefully by X-ray diffraction if suitable crystals can be obtained. One problem which may arise in these systems is that of polymerization, via the bidentate phosphine ligands. In fact, our characterization to date of biradical 5 does not exclude this possibility.(combustion analysis only establishes that the empirical formula is $(\mathrm{P}-\mathrm{P}) \operatorname{Re}(\mathrm{CO})_{3}$ ) Until we can obtain more soluble derivatives for solution molecular weight measurements, this ambiguity will remain, but the possibility of preparing radical polymers is an intriguing one, and their magretic and structural characterization presents a very interesting and challenging problem.

\section{Reactivity of Biradicals}

As noted above, qualitative observations indicate that the reaction of the biradical 5 with hydrogen is faster than the analogous reaction of the monoradicals. This may be evidence of some cooperative effect in the homolysis reaction. This reaction is of considerable interest as a model for the dissociation of hydrogen on metal surfaces. There is some evidence in the literature for such cooperative effects in the more commonly observed thermal reaction of mononuclear metal hydrides to give metal-metal bonded dimers. For example, Vollhardt and Drage have reported that the dinuclear dihydride formed by protonation of the dianion (fulvalene) $\mathrm{Mo}_{2}(\mathrm{CO})_{6}{ }^{2-}$ extrudes hydrogen to form the dimer much faster than the analogous monomer $\left(\eta-\mathrm{C}_{5} \mathrm{H}_{5}\right)(\mathrm{CO})_{3} \mathrm{Mo}-\mathrm{H}$ undergoes the same reaction. This observation was interpreted in terms of cooperative effects on the elimination reaction. In the reaction of the biradicals with hydrogen, we hope to be able to observe various rates of reaction, depending upon the $\mathrm{Re}-\mathrm{Re}$ separation. This will be evaluated by competition experiments, in which the two different dimeric dihydrides formed will be quantified by ${ }^{1} \mathrm{H}$ NMR. In an extreme case such as that of ligand $D$, there will probably be no reaction with hydrogen.

While biradicals formed from ligands $B$ and $C$ may be less reactive toward hydrogen due to the greater metal metal separation, they may be reactive to hydrocarbons such as methane, since the methane reaction presumably does not require such a close approach of the metal centers. This presents the fascinating possibility of a reaction that will activate $\mathrm{C}-\mathrm{H}$ bonds of substrates such as methane, in the presence of hydrogen. This is currently not possible, since all known homogeneous alkane activation systems are much more reactive towards $\mathrm{H}_{2}$ than alkanes. For example, it has been estimated that the well studied alkane activation intermediate produced by photochemical CO loss from $\left(\eta-\mathrm{C}_{5} \mathrm{Me}_{5}\right) \operatorname{Ir}(\mathrm{CO})_{2}$ is more reactive toward $\mathrm{H}_{2}$ than cyclohexane by a factor of $10^{4}$.

Another possibility which will be explored with the biradical prepared from ligand $D$ is that of selective $\mathrm{C}-\mathrm{C}$ bond activation. To date, homogeneous $\mathrm{C}-\mathrm{C}$ bond activation has only been achieved in a very limited set of special circumstances, such as ring opening in cyclopropane and methyl group transfer to give cyclopentadienyl iridium complexes. The biradical prepared from ligand D may be capable of splitting ethane into two rhenium methyl groups. The Re-Re separation of $c a .7 .5$ $\AA$ will provide a reactive pocket of the correct dimensions $(\operatorname{Re}-\mathrm{C}=2.4 \AA$ and $\mathrm{C}-\mathrm{C}$ in ethane $=1.54$ $\AA$ ). A reaction where two Re-C bonds ( $\geq 53 \mathrm{kcal} \mathrm{mol}^{-1}$ each) are formed with cleavage of the C-C bond in ethane $\left(88 \mathrm{kcal} \mathrm{mol}^{-1}\right)$ is thermodynamically feasible. Kinetic feasibility will hopefully be provided by the concerted nature of the bond making and bond breaking processes. 

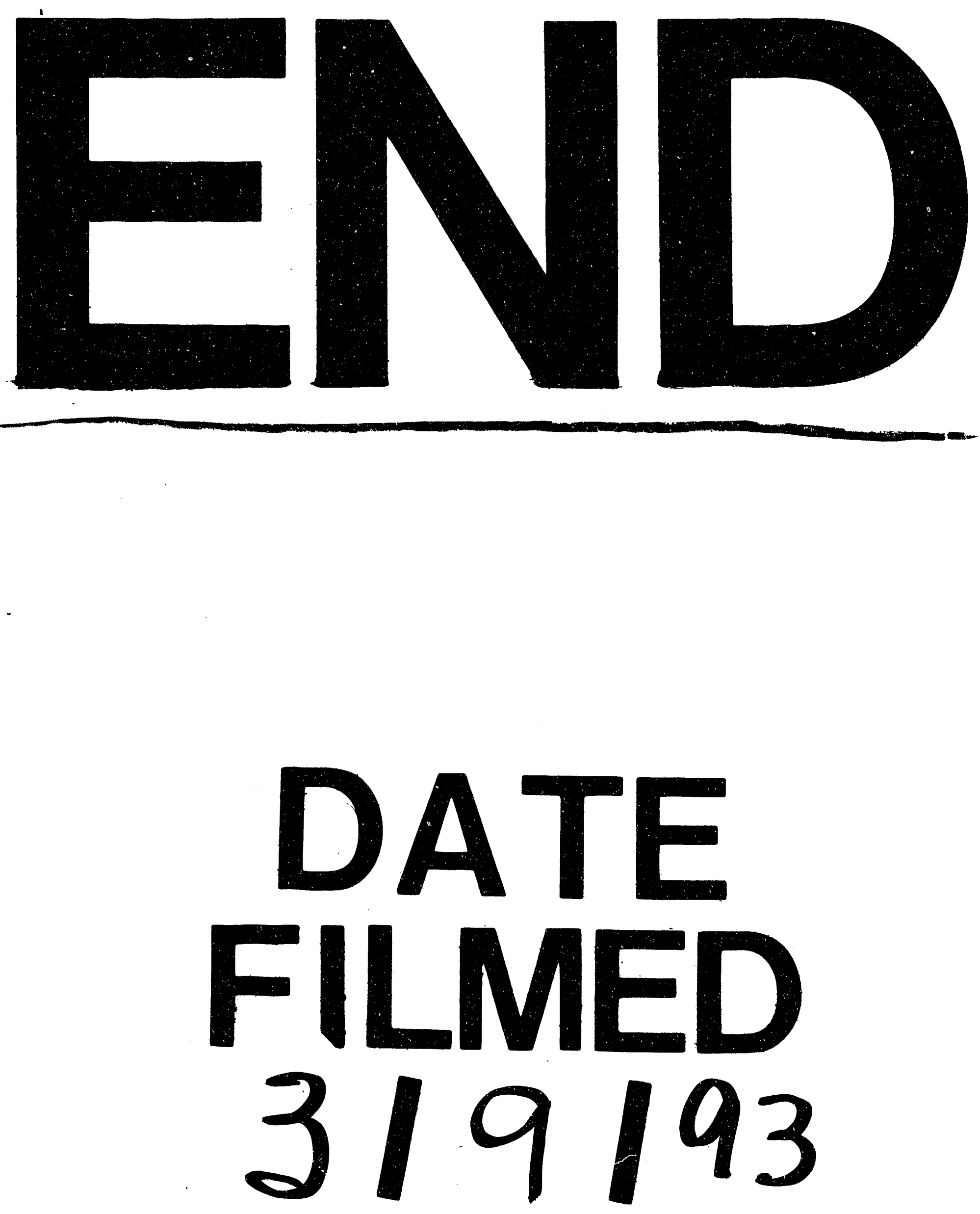
